\title{
Factors Affecting Japanese HPV-Vaccination: Findings from the Semi-Structured Interviews with Adolescent Girls and Caregivers
}

\author{
Rie Wakimizu'1,2*, Kaori Nishigaki2,3, Hiroshi Fujioka',4, Koji Maehara',5, Haruo Kuroki2,6, \\ Tadashi Saito ${ }^{2,7}$, Katsuya Uduki ${ }^{2,8}$ \\ ${ }^{1}$ Faculty of Medicine, University of Tsukuba, Tsukuba, Japan \\ ${ }^{2}$ Investigative Commission of Qualitative Study, Society of Ambulatory and General Pediatrics of Japan, \\ Tokyo, Japan \\ ${ }^{3}$ Faculty of Health Sciences, Tokyo Healthcare University, Tokyo, Japan \\ ${ }^{4}$ Faculty of Health Sciences, Tsukuba International University, Tsukuba, Japan \\ ${ }^{5}$ MAEHARA Pediatric Clinic, Tokyo, Japan \\ ${ }^{6}$ SOTOBO Children's Clinic, Chiba, Japan \\ ${ }^{7}$ Department of Pediatrics, TAKO Central Hospital, Chiba, Japan \\ ${ }^{8}$ SHIROAMU Pediatric Clinic, Kushiro, Japan \\ Email: ${ }^{*}$ riewaki@md.tsukuba.ac.jp
}

Received 28 April 2014; revised 10 June 2014; accepted 27 June 2014

Copyright (C) 2014 by authors and Scientific Research Publishing Inc.

This work is licensed under the Creative Commons Attribution International License (CC BY). http://creativecommons.org/licenses/by/4.0/

(c) (i) Open Access

\section{Abstract}

The objective of the present study was to qualitatively assess the obstructive and facilitative factors affecting adolescent girls and their caregivers when the adolescent had received or was considering receiving the Human Papilloma Virus (HPV) vaccination. Using these data, we propose recommendations for medical and nursing staff concerned with HPV vaccination. Participants were 20 adolescent girls (aged 10 - 19 years) and their caregivers, who had visited any of the 3 pediatric clinics in the Tokyo metropolitan area during a specified period since HPV vaccination began in Japan. The girls and their caregivers were separately interviewed by 2 child and/or family nursing care specialists with a semi-structured interview. The responses were qualitatively analyzed by 2 specialists, and the obstructive and facilitative factors affecting participants' decision to receive HPV vaccination were extracted from the responses. Among the 20 sets of participants, 7 adolescents had completed HPV vaccination, 9 were going to receive vaccination, and 4 had not received any vaccination. The obstructive/facilitative factors related to considering or receiving

"Corresponding author.

How to cite this paper: Wakimizu, R., Nishigaki, K., Fujioka, H., Maehara, K., Kuroki, H., Saito, T. and Uduki, K. (2014) Factors Affecting Japanese HPV-Vaccination: Findings from the Semi-Structured Interviews with Adolescent Girls and Caregivers. Health, 6, 1602-1615. http://dx.doi.org/10.4236/health.2014.613193 
HPV vaccination and actual vaccination were extracted and 4 main categories of factors were identified. Facilitators toward HPV-vaccination of daughters included clear future self-image and visions, fear Cervical Cancer (CC) and desire to escape from CC, having discussion with mothers about HPV-vaccination and CC, and to have a boyfriend. Barriers toward vaccination included the mothers' reluctance to explain the sexual matters about HPV-vaccination to their daughters and difficulty with find the appropriate clinic or hospital to HPV-vaccination. Relevant factors about vaccination included positive family attitudes toward vaccination, having family system allowing consultation and having a public financial support for vaccination for daughters. Our conceptual model adapted from the Katz, et al. conceptual framework integrated the key barriers and facilitators as factors within each of four domains. These four domains have an important link. Especially, the environmental factors and the structural and sociocultural factors domain affect the individual adolescent and the caregiver factors domain, respectively. The results of present study suggest that medical/nursing activities centered on promoting HPV vaccination in Japan should comprehensively cover $\mathrm{CC} /$ vaccination/sex education in an integrated fashion, while schools and public health centers should provide opportunities for caregivers and adolescents to jointly participate in awareness education on HPV vaccination.

\section{Keywords}

\section{Adolescents, Caregivers, HPV Vaccination, Japan, Qualitative Study, Semi-Structured Interview}

\section{Introduction}

Cervical cancer (CC) is the most frequent woman-specific cancer after breast cancer. In Japan, more than 17,000 people develop CC each year, including in-situ cancers, with about 2500 deaths [1]. In recent years, the number of younger people with CC has increased [2].

CC development is associated with Human Papilloma Virus (HPV) infection [3]. Out of approximately 100 types of HPVs known as human-infecting viruses, 30 - 40 are sexually transmitted and 15 are related to cancer development [4] [5]. Type 16 and Type 18 are most frequently detected in CC and jointly accounting for about $70 \%$ of global CC cases [6].

Most sexually transmitted HPVs are removed by the host immune system without manifesting clinical symptoms. HPV is detected in about $45 \%$ of the Japanese general female population aged 15 - 19 years, and the detection rate decreases with age to less than $10 \%$ in women 30 or older [7]. This is because infectious HPV is removed by the immune systems of most healthy women. However, in the cases of compromised immunity or mucosal damage, HPV enters the squamocolumnar junction (SCJ) at the uterine cervix and induces cell mutation. When infected with high-risk Type 16/18 HPV that has not been eliminated from the body, 25\% of women develop moderate dysplasia (CIN2) or high-grade dysplasia intraepithelial cancer (CIN3) within 36 months [8]. HPV that enters the SCJ stem cell proliferates within the cell and undergoes cell division for further proliferation and repeated differentiation. However, HPV particles can only proliferate/differentiate in the cell without forming viremia, and therefore, immunity acquired via natural infection is very weak. Accordingly, the development of a preventive vaccine has been considered highly challenging [9]. Nevertheless, after the development of a human HPV-like particle, antibody induction became possible and accelerated the development of a preventive vaccine.

The currently available vaccines are a bivalent vaccine against HPV-DNA16/18 (Cervarix ${ }^{\circledR}$ ) and a quadrivalent vaccine against HPV-DNA16/18 and additional condylomata acuminata causing 6/11(Gardasil ${ }^{\circledR}$ ) [10] [11]. As these vaccines are artificially manufactured and do not include a DNA genome, they are called subunit vaccines, which are fundamentally different from attenuated or inactivated vaccines. According to clinical study results, a preventive effect of about 100\% against HPV16/18-induced precancerous cervical lesions and CIN2 or higher grade lesions was confirmed in a 5-year follow-up investigation [10]-[13]. According to estimates of the duration of antibody value made using a statistical model based on previous results, the antibody value for HPV16/18 induced by vaccination will be maintained for 20 or more years, which was significantly longer than the level of natural infection [14]. The importance of the age of vaccination was also demonstrated, and the age of 11 - 12 years is recommended for universal vaccination [11]. Cervarix ${ }^{\circledR}$ and Gardasil ${ }^{\circledR}$ have been approved 
and are available in 96 and 123 countries, respectively [10] [11]. In Japan, marketing approval was given to Cervarix $^{\circledR}$ in 2009 and Gardasil ${ }^{\circledR}$ in 2011, and these vaccines have been available since 2010 and 2011, respectively. Both vaccines need to be administered 3 times (Cervarix ${ }^{\circledR}: 0,2$, and 6 months; Gardasil ${ }^{\circledR}: 0$, 1 , and 6 months). In Western countries, all or a part of the vaccination cost is borne by public funds. At the time of the present study, some local governments had just started to subsidize part of the vaccination cost in Japan.

The official HPV vaccination rate is not released on a national level because public funding programs for vaccination are administered by local governments in Japan. However, there are some reports on vaccination rates compiled by local governments that focus on mass vaccination [15] [16]. Compared with other routine vaccination, the HPV vaccination rate is clearly low. Actually, the HPV vaccination rate in young women of age out of public financial support was only 5.4\%, according to a local government report [17].

Some previous studies have reported factors related to HPV vaccination rates. Hughes et al. reported women and wealthy families are more likely to collect information about HPV vaccinations from Internet or advertisements and have more knowledge about HPV vaccinations than men and the needy families [18]. McRee et al. reported having learned about HPV vaccine via the Internet was associated with parents' higher knowledge, positive perceptions of HPV vaccine, and HPV vaccination willingness [19]. Marchand et al. showed that sharing experience of vaccinated women with unvaccinated women was one of the factors that improved awareness of HPV vaccination [20]. On the other hand, according to Darden et al., the most frequent reasons why some adolescents will not receive vaccination against HPV were reported that "Not needed or not necessary" [21]. It has been also shown that the most common reason why parents and their daughters refused HPV vaccination was uncertainty about vaccine safety or concern about potential adverse events [22] [23]. Teitelman et al. reported that beliefs that their health insurance does not cover the HPV vaccine, a long wait to get an appointment, and limited availability of appointments are the barriers to vaccination [24]. Chou et al. reported that the combination of younger age and practice location was strongly associated with completion rates [25]. Liddon et al. investigated the parental underestimation of child's sexual debut and suggested waiting until a parent thinks a child is sexually active could result in missed opportunities for prevention and implications for HPV Vaccine Uptake at age 11 or 12 years [26].

Thus, previous studies have reported promoting or inhibitory factors related to HPV vaccination. However, an effective approach to facilitate HPV vaccination that incorporates health literacy, discussion and relationship between parents and daughters, sex education, information disclosure standard has not been developed. Therefore, the objective of the present study was to qualitatively assess the suppressive/facilitative factors taken into account by female adolescents and their caregivers when considering or receiving HPV vaccination in light of health literacy, the adolescent-caregiver relationship, living standards, and information transmitted from the school or clinic, community, etc. The findings of the present study are very important for healthcare providers to develop and practice enlightenment activities and educational interventions for promoting HPV vaccination to adolescents and their caregivers.

\section{Methods}

\subsection{Participants}

The participants were recruited from three pediatric clinics in Tokyo metropolitan area in the period 2011 spring-2012 spring. The interviewer did not engage directly in the health-care professional practices for the participants in the institution.

The criteria for inclusion in the study were as follows: a) adolescent girls who are 10 to 19 years and received at least one HPV vaccination that was started in December 2009 and their caregivers, or b) adolescent girls who are 10 to 19 years and knew about the HPV vaccine, but decided not to undergo vaccination and their caregivers; 1) living with family in the community; 2) assessed their mental and intellectual status by physicians to determine their fitness for participation in the study; 3) able to give informed consent; and 4) able to participate in an interview in Japanese.

For recruitment purposes, we asked the physicians to recruit those adolescents and caregivers whom the physician believed had met the inclusion criteria. If adolescents and caregivers were interested in the study, the interviewers had permission to contact caregivers by telephone. A meeting was then held with the potential participants, and they were provided with information about the study and on ethical issues. Twenty-one pairs agreed to participate in this study. One pairs was excluded from the study due to failure to set the schedule. Informed consent was obtained from the participants respectively. 


\subsection{Data Collection}

We used theoretical sampling to recruit the participants [27]. In theoretical sampling, the participants who are likely to provide data similar to or in contrast to the existing data are sampled. For example, with the physicians' help, we recruited adolescents who received HPV vaccination by their private expense without government support after collecting a certain amount of data on the adolescents who received HPV vaccination with government support.

We contacted 21 adolescents, 20 of whom agreed to participate in the study. The data were collected in the period 2011 summer-2012 spring, using narrative interviews [28]. Each of the 20 participants was interviewed once. A semi-structured interview is a method of research used in the social sciences. While a structured interview has a rigorous set of questions which does not allow one to divert, a semi-structured interview is open, allowing new ideas to be brought up during the interview as a result of what the interviewee says. The interviewer in a semi-structured interview generally has a framework of themes to be explored. However, the specific topic or topics that the interviewer wants to explore during the interview should usually be thought about well in advance especially during interviews for research projects. It is generally beneficial for interviewers to have an interview guide prepared, which is an informal grouping of topics and questions that the interviewer can ask in different ways for different participants. Interview guides help researchers to focus an interview on the topics at hand without constraining them to a particular format. Therefore, we prepared an interview guide so that the interviews would be conducted with some degree of conformity. To ensure the quality of the guide, we discussed it with specialists who were engaged directly in providing professional health-care practices to children and families. The framework of the interview comprised two dimensions:

\subsubsection{Level of Knowledge on CC and the HPV Vaccine}

(Questionnaire) Read A) to G) texts below and choose Correct, Wrong, or Unknown.

1) CC is mainly caused by infection with HPV (human papilloma virus).

2) HPV infection is transmitted primarily by sexual intercourse.

3) About $80 \%$ of adult women have been infected with HPV at least once.

4) CC is increasing in women in their $20 \mathrm{~s}$ and $30 \mathrm{~s}$ in Japan.

5) HPV vaccine can prevent about $60 \%$ of CC.

6) CC can be cured $100 \%$ and does not affect pregnancy or delivery if detected early.

7) Even if you receive HPV vaccination, you have to undergo CC screening.

\subsubsection{Expression of Awareness, Attitudes (Behaviors), and Resources}

1) When and how did you find out about the HPV vaccine?

2) Do you know the purpose of HPV vaccination?

a) Do you know what it is for? b) When and how did you find out about it?

3) Did you want (your daughter) to have HPV vaccination? Why or Why not?

4) What do you think about the HPV vaccine being available in Japan for cancer prevention?

5) Is HPV vaccination necessary for you? Why or Why not?

6) Were you anxious about or afraid of having HPV vaccination? Describe specifically.

(For those vaccinated) What did you feel when you were vaccinated?

7) Before you received HPV vaccination, did you talk about it with your family or friends? What did you talk about?

8) What was the attitude of your family and friends regarding HPV vaccination?

We posed open-ended questions (except questions about CC and the HPV vaccine). The answers to the questions were checked after the interview. When the subject of vaccination expense came up in conversation during the interview, the interviewer asked about participants' preferred amount of self-pay and public financial support. The interviews were conducted in a private room at institutions. The mean duration of the interviews was 45 min. With the participants' permission, interviews were tape-recorded and transcribed verbatim by the principal author.

\subsection{Data Analysis}

To analyze the data, we used the descriptive statistics analysis and the qualitative content analysis. We read and 
reviewed the transcribed interviews for themes and codes in a two-part process.

First, a conceptual model of factors affecting the HPV vaccine acceptability, based on a HPV Vaccine Perception, Accountability and Adherence Model, was revised and used to develop a set of themes and codes [29]. Next, transcripts were independently reviewed by two researchers, and a set of passages from each transcript were thematically classified into each theme-code pair as they related to the following four themes: individual adolescent factors, caregiver factors, structural and sociocultural factors, environmental factors. All researchers then met to review these classifications and resolve disagreements. Finally, we all made a conceptual model of factors affecting HPV vaccination in primary care settings and developed a set of themes and codes.

We analyzed the verbatim data in Japanese. All of the theme-code pairs that were provided by the participants' narratives, which appear in this article, were also originally in Japanese. We translated these into English (they were edited and proofread by a professional) so that they could be read by international researchers. To ensure the accuracy and validity of the data analysis, the principal author analyzed the data under constant discussion with other authors. Furthermore, we sent the results to two participants for member-checking. Their feedback indicated that the categories that were developed by the authors adequately reflected the experiences of the two participants.

\subsection{Ethical Considerations}

We received approval for the study through the ethics committee of the Society of Ambulatory and General Pediatrics of Japan. We informed each adolescent and caregiver, both verbally and in writing, about the purpose of the study and assured the participants that their information would be treated confidentially. We also informed them that their participation in the study was voluntary and that refusal to participate would not disadvantage them.

\section{Results}

We interviewed 20 vaccinated/unvaccinated adolescents of school age between 12 - 17 years old and caregivers aged between 36-57 years lived in the wider Tokyo area, Japan. The characteristics of the study participants are shown in Table 1. The mean age of the adolescents was 14.9 years (standard deviation, SD: 1.5, range: 12 - 17). The mean age of the caregivers was 45.1 years (SD: 5.5, range: 36 - 57). Eight adolescents completed all three HPV vaccinations. Another eight adolescents completed the first or second vaccination with at least one injection left undone. Four adolescents had no vaccination including pendency.

A summary of adolescents and caregivers interview outcomes are shown in Table 2 and more detailed results are presented in the following sections. Please note that the qualitative nature of interview results does not easily allow for exact quantification of responses. In the present study, when we state that "some," "many," or "most" participants provided a given response the approximate percentages are 40, 70 and 90 percent, respectively.

\subsection{Individual Adolescent Factors}

Many of the adolescents felt that the information provided prior to vaccination was difficult to understand only by briefly reading the material or listening to the content, and knowledge differed from person to person. Some of the adolescents did nothing further after finding it difficult to understand the material, while others proactively tried to get more information by repeatedly reading through the material, searching the internet, or asking questions to the teacher or caregivers. Those who did not receive the vaccination had less knowledge.

The adolescents who voluntarily wished to be vaccinated had future self-image and visions, such as "I want to travel all around the world as a career woman" and "I want to have a baby in future.” These individuals received vaccination for the reason of positively preventing CC. Several of the vaccinated adolescents had learned from acquaintances or TV documentaries about patients' experiences with CC and strongly expressed their fear of and desire to escape from CC. Meanwhile, other adolescents said, "I cannot get a concrete picture of what CC really is as nobody near me had the disease" or "what is CC at all?" Some of their comments were "if I could have a concrete image of CC, I would have been more positive in receiving HPV vaccine" and "I wish that the memories written by CC patients or the videos on CC had been available, together with the explanation of the vaccine." Most in the vaccination group had recognized the value of the HPV vaccine, although they also distrusted the HPV vaccine due to very few evidences of HPV vaccine that had just been introduced in Japan recently. Many 
Table 1. Characteristics of study participants.

\begin{tabular}{|c|c|c|c|c|c|c|c|}
\hline $\begin{array}{l}\text { Identification } \\
\text { no. }\end{array}$ & $\begin{array}{l}\text { Adolescent's } \\
\text { age (years) }\end{array}$ & $\begin{array}{l}\text { Caregiver's } \\
\text { age (years) }\end{array}$ & $\begin{array}{l}\text { School } \\
\text { attended by } \\
\text { the girl }\end{array}$ & $\begin{array}{l}\text { Adolescent's status } \\
\text { of HPV vaccination }\end{array}$ & $\begin{array}{l}\text { Adolescent's } \\
\text { health issue }\end{array}$ & $\begin{array}{l}\text { Subsidy from the } \\
\text { national and local } \\
\text { government }\end{array}$ & $\begin{array}{l}\text { Family } \\
\text { situation }\end{array}$ \\
\hline 1 & 17 & 39 & High school & $\begin{array}{l}\text { Under vaccination } \\
\text { (two injections) }\end{array}$ & & None & \\
\hline 2 & 14 & 39 & $\begin{array}{l}\text { Junior high } \\
\text { school }\end{array}$ & $\begin{array}{c}\text { Completed } \\
\text { (all three injections) }\end{array}$ & Asthma & $\begin{array}{l}\text { Full amount } \\
\text { of the expenses }\end{array}$ & $\begin{array}{l}\text { Single-female-parent, } \\
\text { three-generation family }\end{array}$ \\
\hline 3 & 12 & 46 & $\begin{array}{l}\text { Junior high } \\
\text { school }\end{array}$ & $\begin{array}{l}\text { Under vaccination } \\
\text { (one injection) }\end{array}$ & $\begin{array}{l}\text { Asthma, atopic } \\
\text { dermatitis }\end{array}$ & $\begin{array}{l}90 \% \text { of } \\
\text { the expenses }\end{array}$ & \\
\hline 4 & 16 & 55 & High school & $\begin{array}{c}\text { Completed } \\
\text { (all three injections) }\end{array}$ & & None & \\
\hline 5 & 14 & 43 & $\begin{array}{l}\text { Junior high } \\
\text { school }\end{array}$ & $\begin{array}{l}\text { Under vaccination } \\
\text { (one injection) }\end{array}$ & $\begin{array}{c}\text { Congenital } \\
\text { hypothyroidism }\end{array}$ & $\begin{array}{l}90 \% \text { of } \\
\text { the expenses }\end{array}$ & \\
\hline 6 & 13 & 45 & $\begin{array}{l}\text { Junior high } \\
\text { school }\end{array}$ & $\begin{array}{l}\text { Completed } \\
\text { (all three injections) }\end{array}$ & & $\begin{array}{c}90 \% \text { of } \\
\text { the expenses }\end{array}$ & \\
\hline 7 & 14 & 37 & $\begin{array}{l}\text { Junior high } \\
\text { school }\end{array}$ & $\begin{array}{l}\text { Under vaccination } \\
\text { (one injection) }\end{array}$ & & $\begin{array}{c}90 \% \text { of } \\
\text { the expenses }\end{array}$ & \\
\hline 8 & 14 & 47 & $\begin{array}{l}\text { Junior high } \\
\text { school }\end{array}$ & $\begin{array}{c}\text { Completed } \\
\text { (all three injections) }\end{array}$ & & None & \\
\hline 9 & 16 & 45 & High school & $\begin{array}{l}\text { Under vaccination } \\
\text { (two injections) }\end{array}$ & Asthma & $\begin{array}{l}\text { Full amount } \\
\text { of the expenses }\end{array}$ & Single-female-parent \\
\hline 10 & 16 & 41 & High school & $\begin{array}{l}\text { Completed } \\
\text { (all three injections) }\end{array}$ & & $\begin{array}{l}\text { Full amount } \\
\text { of the expenses }\end{array}$ & Three-generation family \\
\hline 11 & 16 & 45 & High school & $\begin{array}{l}\text { Under vaccination } \\
\text { (two injections) }\end{array}$ & & $\begin{array}{l}\text { Full amount } \\
\text { of the expenses }\end{array}$ & \\
\hline 12 & 17 & 44 & High school & $\begin{array}{l}\text { Under vaccination } \\
\text { (one injection) }\end{array}$ & & $\begin{array}{l}\text { Full amount } \\
\text { of the expenses }\end{array}$ & Three-generation family \\
\hline 13 & 14 & 53 & $\begin{array}{l}\text { Junior high } \\
\text { school }\end{array}$ & $\begin{array}{l}\text { Under vaccination } \\
\text { (two injections) }\end{array}$ & & $\begin{array}{l}\text { Full amount } \\
\text { of the expenses }\end{array}$ & Three-generation family \\
\hline 14 & 13 & 43 & $\begin{array}{l}\text { Junior high } \\
\text { school }\end{array}$ & $\begin{array}{l}\text { Under vaccination } \\
\text { (one injection) }\end{array}$ & & $\begin{array}{l}\text { Full amount } \\
\text { of the expenses }\end{array}$ & Three-generation family \\
\hline 15 & 14 & 50 & $\begin{array}{l}\text { Junior high } \\
\text { school }\end{array}$ & Unvaccinated & & $\begin{array}{l}90 \% \text { of the } \\
\text { expenses }\end{array}$ & \\
\hline 16 & 17 & 57 & High school & Unvaccinated & & None & \\
\hline 17 & 14 & 43 & $\begin{array}{l}\text { Junior high } \\
\text { school }\end{array}$ & Unvaccinated & Asthma & $\begin{array}{l}90 \% \text { of the } \\
\text { expenses }\end{array}$ & $\begin{array}{l}\text { Single-female-parent, } \\
\text { on public assistance }\end{array}$ \\
\hline 18 & 17 & 45 & High school & $\begin{array}{c}\text { Completed } \\
\text { (all three injections) }\end{array}$ & & None & \\
\hline 19 & 14 & 36 & $\begin{array}{l}\text { Junior high } \\
\text { school }\end{array}$ & Unvaccinated & & $\begin{array}{l}90 \% \text { of the } \\
\text { expenses }\end{array}$ & \\
\hline 20 & 16 & 49 & High school & $\begin{array}{l}\text { Completed } \\
\text { (all three injections) }\end{array}$ & & $\begin{array}{l}90 \% \text { of the } \\
\text { expenses }\end{array}$ & \\
\hline
\end{tabular}

of the adolescents obtained information on post-vaccination pain from the vaccinated people and had anxiety regarding IM injection. One adolescent said, "I wanted to get away from injection when I learned that it will be very painful and that I will have to receive as many as 3 injections.”

The adolescents who already had boyfriends accepted HPV vaccination, regardless of their age or relationship situation. However, the adolescents who did not have a boyfriend or who had no plan to get a boyfriend told their caregivers that "vaccination is not necessary now," or "I can wait for some more time." The adolescents whose menstruation had not started yet after they entered junior high school told their caregivers that they wanted to postpone vaccination, as they were aware of their slow sexual growth.

A greater number of adolescents in the vaccination group had discussed CC and HPV vaccine with their caregivers, while some in the unvaccinated group had not seriously discussed HPV vaccination with caregivers at all. 
Table 2. Interview outcomes.

\section{Individual adolescent factors}

\section{Facilitative}

Have knowledge about CC and HPV vaccine

Try to get more information

Have future self-image and visions

Express fear and desire to escape from CC

Recognize the value of the HPV vaccine

Already have boyfriends

Discuss CC and HPV vaccine with their caregivers

Express willingness to accept HPV vaccination to their caregivers

Prioritize the caregiver's thinking on HPV vaccination

Regularly visit the clinic

\section{Caregiver factors}

\section{Facilitative}

Have basic understanding about the effectiveness of HPV vaccination against CC

Be aware of the increasing prevalence of CC

in the Japanese younger generations

Be deprived of the future childbearing opportunities due to CC

Know that HPV vaccination was recommended

before the start of sexual intercourse

Have expectation for the effects of vaccination

Have fears against cancer

Adolescents have boyfriends

Believe the adolescents had not yet had any sexual relationships

Unilateral decision on the adolescents' HPV vaccination

Be trust in doctors' recommendations for HPV vaccination

Doctors' responses to caregivers' questions about HPV vaccination

\section{Obstructive}

Have less knowledge about CC and HPV vaccine

Do not get a concrete picture of what CC really

Distrust the HPV vaccine

Have anxiety regarding IM injection

Do not have a boyfriend or have no plan to get a boyfriend

Be aware of slow sexual growth

Do not seriously discuss HPV vaccination with caregivers

Have psychological anguish

Distrust the HPV vaccine

Adolescent girls did not have any boyfriends

Respect the adolescents’ opinions

Feel difficult to explain HPV vaccine to the adolescents

Feel embarrassed explaining the detail of sexual intercourse

Easy to locate the hospital 


\section{Continued}

Structural and sociocultural factors

Facilitative

Obstructive

Families maintain a proactive stance toward immunization

Caregivers consult other family members

regarding adolescents' HPV vaccination

Caregivers and adolescents maintain good relationships

Availability of public financial support for HPV vaccination

Family do not allow for the expensive cost

for adolescents' HPV vaccination

Caregivers have difficulty adjusting their schedule with the adolescents' schedule

Environmental factors

Facilitative

Obstructive

Various government publicity materials on HPV vaccination

Diffusion of information on CC and

the HPV vaccine by internet, TV, and other media

Experience peer pressure

Hear the bad publicity regarding the HPV vaccine

Under peer pressure, some adolescents expressed willingness to accept HPV vaccination to their caregivers, as most of their classmates had already been vaccinated or their best friends were planning for vaccination. In half of the cases, the caregivers took the initiative, and vaccination was not an unpleasant experience for the adolescents who prioritized the caregiver's thinking on HPV vaccination. One individual in the unvaccinated group was school-phobic and told the interviewer about her psychological anguish, including conflict with caregivers, a complicated family situation where she had to take care of a younger brother, and bullying by classmates. The adolescents who regularly visited the clinic for asthma or other chronic illnesses had been informed about HPV vaccination early and directly through their physicians' explanations.

\subsection{Caregiver Factors}

All caregivers of adolescents had basic understanding about the effectiveness of HPV vaccination against CC. The caregivers had no reservations about the adolescents' vaccination when they were aware of the increasing prevalence of CC in the Japanese younger generations, when they were afraid that adolescents might be deprived of the future childbearing opportunities due to CC, or when they knew that vaccination was recommended before the start of sexual intercourse. Further, based on their knowledge about HPV vaccination, the caregivers stated their concerns about long-term safety and side effects of vaccination due to the lack of evidence in Japan, which were the barriers for vaccination. Some caregivers had reservations because of lack of knowledge, thinking that the uterine cervix would be the injection site. Even if these issues were obstructive factors, they decided on vaccination when their expectation for the effects of vaccination outweighed their concerns about the negative aspects of vaccination. The caregivers with strong fears against cancer said that they were willing to pay for vaccination by themselves if it would prevent cancer.

When the adolescents had boyfriends, the caregivers did not feel that the vaccination timing was too early. Some of the caregivers whose adolescent girls did not have any boyfriends said that it would be easier to have the adolescents vaccinated during their junior high school days when they believed the adolescents had not yet had any sexual relationships. Nevertheless, the caregivers whose adolescent girls had no boyfriends thought that vaccination could wait until later, as the caregivers did not know about recommendation for vaccination prior to the start of sexual relationships.

Some caregivers thought that there would be no problem with their unilateral decision on the adolescents' HPV vaccination. As these caregivers did not have to worry about how to explain the significance of vaccination to the adolescents, they immediately made appointments with the clinic once the decision was made. Therefore, this belief of the caregivers worked as a facilitating factor. Meanwhile, the caregivers who respected the adoles- 
cents' opinions discussed the HPV vaccination with the adolescents, although they felt embarrassed explaining the detail of sexual intercourse. The caregivers who were aware of their lack of knowledge about CC and HPV vaccine felt that it was difficult to explain HPV vaccine to the adolescents, as a high level of medical knowledge was required.

The caregivers whose adolescent girls had regularly visited the clinic could promptly obtain HPV vaccine information from the clinic bulletin board or attending physician. The facilitating factors in these cases were trust in the doctors' recommendations for HPV vaccination and the doctors' responses to the caregivers' questions about HPV vaccination.

In all the cases of vaccination, caregivers searched for the hospital and appointments for the adolescents' HPV vaccination, although the caregivers said that it was not easy to locate the hospital. The caregivers expressed their wish for a list of the hospitals in each area that could provide HPV vaccination. They preferred information on pediatricians rather than gynecologists because they felt it would be easier to take the adolescents to pediatricians.

\subsection{Structural and Sociocultural Factors}

Most of the families in the vaccination group maintained a proactive stance toward immunization and had their children receive vaccination whenever possible, regardless of the type of vaccines. Some of the caregivers in the vaccination group reported that they had consulted their spouse or other family members about their concerns regarding HPV vaccination (adverse reactions, financial cost, etc.). In all cases, the caregivers were directly involved in decision-making about the adolescents' vaccination, while other family members were consulted about vaccination and eased the caregivers' concerns, thus indirectly facilitating the adolescents' vaccination.

In the cases of caregivers and adolescents who maintained good relationships in their everyday lives, the caregivers' explanation before vaccination and discussion between caregiver and adolescent were sufficiently carried out. Furthermore, the financial situation of the family was one of the influencing factors for the decision of vaccination. When a family with multiple adolescents within the ages recommended for HPV vaccine was planning for self-pay, the expensive cost for HPV vaccination was a prohibiting factor. Availability of public financial support for HPV vaccination was another facilitating factor for the caregivers who were willing to encourage the adolescents to receive vaccination. Some caregivers had the adolescents wait until public financial support became available, while others prompted the adolescents to receive vaccination as soon as possible, in case the public financial support system was discontinued.

Some caregivers said that it was difficult to adjust their schedule with the adolescents' schedule, as vaccination required 3 hospital visits. Some expressed their wish for collective vaccination at school because of the scheduling difficulty owing to the caregivers' full-time jobs and the adolescents' club activities and school attendance.

\subsection{Environmental Factors}

Vaccine acceptability of caregivers and adolescents was enhanced by various government publicity materials on HPV vaccination (subsidy information included); diffusion of information on CC and the HPV vaccine by internet, TV, and other media; information provided by local governments, schools, and clinics; and peer pressure from classmates and caregivers' friends. In fact, many of the unvaccinated adolescents had very limited access to government publicity or information and made no attempt to obtain the information. The adolescents and caregivers thought about cancelling vaccination at least once when they learned from the people around them about the bad publicity regarding the HPV vaccine, including its adverse reactions and unreliability. Most of the caregivers wanted to get information on the HPV vaccine from their family doctors or school healthcare or welfare specialists, while many adolescents wanted to get information from female healthcare professionals.

\section{Discussion}

The results of our study on promoting factors to Japanese HPV vaccination corroborate the findings of previous research; collecting more information and having more knowledge about HPV vaccinations [18], positive perceptions of HPV vaccine and HPV vaccination willingness [19], developmental maturity [29], and peer pressure [20]. On the other hand, the results of our study on obstructive factors to Japanese HPV vaccination corroborate 
the findings of previous research; the awareness of "Not needed or not necessary" [21], uncertainty about vaccine safety or concern about potential adverse events [22] [23], the parental underestimation of child's sexual debut and waiting attitude until a parent thinks a child is sexually active, beliefs that their health insurance does not cover the HPV vaccine, far practical location, and a long wait to get an appointment [24] [25].

Our conceptual model, shown in Figure 1, is adapted from the Katz, et al. conceptual framework [29]. Our model integrates the key barriers and facilitators within each of four domains selected for this study, based on our results. As depicted in Figure 1, we propose that both the vaccine acceptability and the actual vaccination are influenced by the facilitators and barriers in each of the four domains. These four domains have an important link. Especially, the environmental factors and the structural and sociocultural factors domain affect the individual adolescent and the caregiver factors domain, respectively.

Our findings provide a concurrent perspective on HPV vaccination from both subsidy eligible adolescents and the caregivers who lead them. The impression from our study participants was generally favorable towards HPV vaccination. Nevertheless, we found important facilitators and barriers among both individual adolescents and caregivers (see Table 2 and Figure 1).

Individual adolescents factors affecting HPV vaccination in primary care settings were as follows: "Knowledge," "Information seeking attitude," "Health beliefs," including "Future self-image and visions" and "Image of CC," "Existence of a boyfriend," "Developmental maturity," "Relatedness to caregiver," "Mental health,” and "Healthcare utilization." Some of these items had been included in the conceptual framework of Katz, et al. [29]. Influential factors that have been newly identified in the present study were as follows: "Information seeking attitude," "Future self-image and visions," "Image of CC," and "Existence of a boyfriend." "Information seeking attitude" was shown previously to be strongly related to the amount of knowledge of the person [30]. Adolescents need to become interested in HPV vaccination in order to acquire the "Information seeking attitude," and the question here is how the healthcare professionals can raise their interest. All of the adolescents who voluntarily applied for HPV vaccination had clear "Future self-image and visions." This was a new finding. For these adolescents, HPV vaccination may have been an essential step to ensure that their future visions would definitely become a reality. The following opinions were given in relation to "Image of CC": "I could have been more positive in receiving HPV vaccination, if I had had a more concrete CC image" and "I wished that the memoirs or videos on the experience of CC patients had been available, together with CC explanation”. Healthcare professionals should listen to these voices and consider providing a tool or presentation material that can clearly show the "Image of CC" when they are explaining HPV vaccination. Furthermore, intervention with such tools or presentations would also be useful for caregivers, as their knowledge will increase and they will be more confident in discussing the matter with the adolescents.

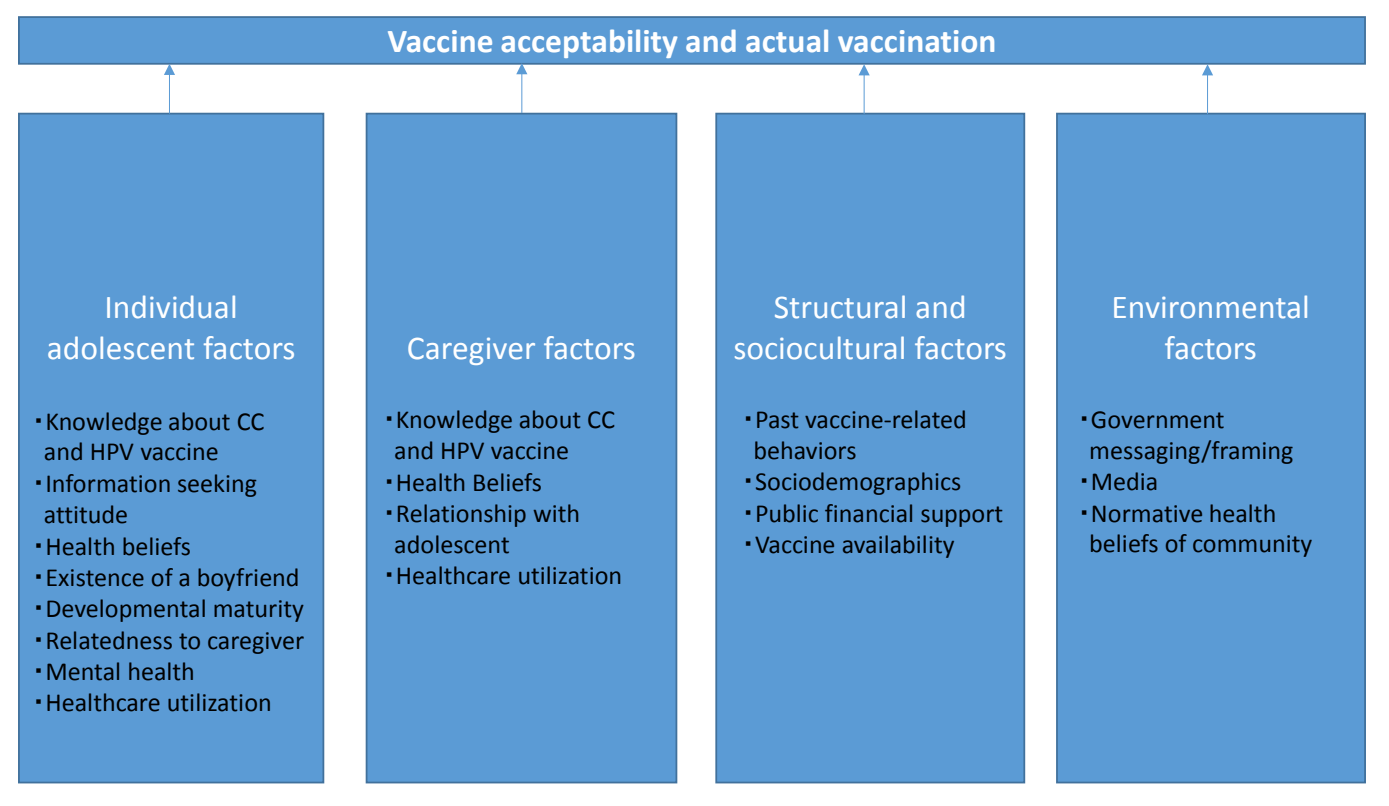

Figure 1. Our conceptual model of factors affecting HPV vaccination in primary care settings. 
Although the "Existence of a boyfriend" of the adolescent was not included in the overseas review documents as an influential factor for HPV vaccination, the adolescents who had boyfriends received vaccination without any reservation in the present study, regardless of whether sexual debut had been experienced. In contrast, the adolescents who did not have boyfriends and had no plan to have boyfriends tended to postpone vaccination. Therefore, healthcare professionals should accurately communicate the ages recommended for vaccination and the duration of drug efficacy to encourage those with no boyfriends to be vaccinated on schedule. Additionally, the "Existence of a boyfriend" of the adolescent influenced the caregiver's decision on vaccination. According to a previous study in America, about half of caregivers wanted to convey intercourse-related information to adolescents directly by themselves [31]. In contrast, the caregivers and adolescents in the present study hesitated to talk about sexual matters and wanted the school medical staff to give the explanation including sexual matters. In the preceding overseas studies, the perception that HPV vaccination would encourage sexual conduct was an obstructive factor [32] [33], which was not the case in Japan. As demonstrated by these observations, cultural characteristics of each country should be taken into consideration in planning HPV vaccination promotion. In Japan, the explanation on HPV vaccination and sexual matters by the medical staff of schools is considered effective in facilitating the decision to vaccinate by adolescents and caregivers.

In the cases of decisions made solely by caregivers, the caregiver's explanation to the adolescent was omitted, and therefore the caregivers did not have any difficulty in explanation. In this case, the caregiver's unilateral decision worked as a facilitating factor. However, because the adolescent did not give any informed assent, the vaccination could not be considered the adolescent's proactive initiative. It will be important to encourage adolescents to take the initiative for vaccination as well as other health measures because, they should regularly receive cervical cancer screening tests for future CC prevention in addition to HPV vaccination [34]. The adolescents should take the initiative in receiving HPV vaccination to establish the basis for continuous prevention of $\mathrm{CC}$ after they become independent of caregivers. Consequently, the caregiver and adolescent should discuss the HPV vaccine prior to vaccination. As in previous studies [35], the present study showed that the caregiver's decision on the adolescent's vaccination was facilitated by the consultation with their pediatrician and the information available from the nearby medical institution. Therefore, the physicians or nurses responsible for primary care should communicate correct information regarding HPV vaccination in an easy-to-understand manner so that the caregiver and adolescent will be able to have a discussion before vaccination.

Structural and sociocultural factors affecting an adolescent's HPV vaccination in the primary care setting were as follows: "Past vaccine-related behaviors"; "Sociodemographics" which consisted of "Opportunity for discussion in the family," "Caregiver-adolescent relationship," and "Circumstance of life"; "Public financial support”; "Sociogeographics"; and "Vaccine availability". Most of these factors were given in the conceptual framework of Katz, et al. [29]. A new environmental factor documented in the present study was "Public financial support." At the time of our survey, public financial support was gradually expanding [15], and there were differences among local governments in the amount of financial support and the range of eligible age. In the cases of no public financial support, the caregivers understandably were not willing to pay 50,000 yen over 6 months for 3 vaccinations, considering their family finances and the existence of sisters close in age in the family. Therefore, many of the participants tried to postpone or accelerate the timing of vaccination in accordance with the schedule of public financial support. At present, HPV vaccination is included in the national routine immunization program, and children from the sixth grade of primary school to the first grade of senior high school are eligible for financial support. As suggested by the results of the individual adolescents' factors, physical maturity and sexual activity are substantially different from child to child, and therefore the healthcare professionals should intervene, taking into account the appropriate timing of recommending vaccination for each case. When the information material is distributed to all adolescents, a consultation booth or phone number will be essential to provide individual support. Taking into account the caregiver's remark that "it is difficult to take an adolescent to the gynecologist," healthcare professionals should provide a map of local pediatricians and internists that can provide HPV vaccination. As both parents are working in an increasing number of households, it may be difficult to adjust working schedules for the 3-injection program, as indicated by many participants. Therefore, collective vaccination at school should be considered as a possible solution in the future.

Environmental factors affecting adolescent girls' HPV vaccinations in the primary care setting were as follows: "Government messaging/framing," "Media," and "Normative health beliefs of community.” These factors were included in the conceptual framework of Katz, et al. [29]. In the present study, vaccine acceptability of the adolescent and caregiver was enhanced by various government publicity materials on HPV vaccination (includ- 
ing public financial support); diffusion of information on CC and the HPV vaccine by the internet, TV, and other media; information provided by local schools and family doctors; and peer pressure from classmates and caregivers' friends. Furthermore, the information on HPV vaccine seemed easily available for the caregivers whose adolescent girls had regular health checkups. In contrast, the caregivers of unvaccinated adolescents did not pay much attention to government publicity, media information, or the health beliefs in society. Meanwhile, adolescents and caregivers thought about cancelling vaccination when they learned from the people around them about the bad publicity of vaccination including its adverse reactions and unreliability. Based on these findings, the healthcare professionals should provide correct information on HPV vaccination not only to the target adolescents and caregivers but also to the general public in the community. During the dissemination of information, attention should be paid to the characteristics of the Japanese people who are not willing to talk about sexual behaviors within the family, especially between parent and child, and substantial sexual behavior-related explanations should also be provided with regards to CC and HPV vaccination.

\section{Conclusion}

In conclusion, we can say that we could report the results of the characteristics of factors affecting Japanese HPV and identify individual adolescent factors, structural and sociocultural factors, caregiver factors and environmental factors which have an effect on HPV vaccination. However, the number of the participants was not high enough. And only those who visited pediatric clinics and were recruited by the doctor were chosen as the participants of this study. Therefore, it is possible that adolescents and caregivers who did not visit a doctor during the recruitment period and/or who did not share a trusting relationship with their doctor (for example, from whom the doctor found it awkward to seek participation) were eliminated from the participant group. Cautions are required for the generalization from the findings of this research.

\section{References}

[1] Foundation for Promotion of Cancer Research (2013) Cancer Statistics in Japan 2013. http://ganjoho.jp/data/professional/statistics/backnumber/2013/cancer_statistics_2013.pdf

[2] Health, Labour \& Welfare Ministry (2013) An Interim Report of Panel to Discuss the Future of Cancer Screening 2013. http://www.mhlw.go.jp/file.jsp?id=148160\&name=2r98520000035gsk_1.pdf

[3] Bosch, F.X., Lorincz, A., Muñoz, N., Meijer, C.J. and Shah, K.V. (2002) The Causal Relation between Human Papillomavirus and Cervical Cancer. Journal of Clinical Pathology, 55, 244-265. http://dx.doi.org/10.1136/jcp.55.4.244

[4] Wiley, D.J., Douglas, J., Beutner, K., Cox, T., Fife, K., Moscicki, A.B. and Fukumoto, L. (2002) External Genital Warts: Diagnosis, Treatment, and Prevention. Clinical Infectious Diseases, 35, S210-224. http://dx.doi.org/10.1086/342109

[5] Schiffman, M. and Castle, P.E. (2003) Human Papillomavirus: Epidemiology and Public Health. Archives of Pathology Laboratory Medicine, 127, 930-934.

[6] Muñoz, N., Bosch, F.X., Castellsagué, X., Díaz, M., de Sanjose, S., Hammouda, D., Shah, K.V. and Meijer, C.J. (2004) Against Which Human Papillomavirus Types Shall We Vaccinate and Screen? The International Perspective. International Journal of Cancer, 111, 278-285. http://dx.doi.org/10.1002/ijc.20244

[7] Inoue, M., Sakaguchi, J., Sasagawa, T. and Tango, M. (2006) The Evaluation of Human Papillomavirus DNA Testing in Primary Screening for Cervical Lesions in a Large Japanese Population. International Journal of Gynecological Cancer, 16, 1007-1013. http://dx.doi.org/10.1111/j.1525-1438.2006.00460.x

[8] Winer, R.L., Kiviat, N.B., Hughes, J.P., Adam, D.E., Lee, S.K., Kuypers, J.M. and Koutsky, L.A. (2005) Development and Duration Of Human Papillomavirus Lesions, After initial Infection. The Journal of Infectious Diseases, 191, 731738. http://dx.doi.org/10.1086/427557 http://jid.oxfordjournals.org/content/191/5/731.long

[9] Stanley, M., Lowy, D.R. and Frazer, I. (2006) Chapter 12: Prophylactic HPV Vaccines: Underlying Mechanisms. Vaccine, 24, S106-S113. http://dx.doi.org/10.1016/j.vaccine.2006.05.110

[10] Garland, S.M., Hernandez-Avila, M., Wheeler, C.M., Perez, G., Harper, D.M., Leodolter, S., Tang, G.W., Ferris, D.G., Steben, M., Bryan, J., Taddeo, F.J., Railkar, R., Esser, M.T., Sings, H.L., Nelson, M., Boslego, J., Sattler, C., Barr, E. and Koutsky, L.A. (2007) Quadrivalent Vaccine against Human Papillomavirus to Prevent Anogenital Diseases. The New England Journal of Medicine, 356, 1928-1943. http://dx.doi.org/10.1056/NEJMoa061760

[11] Paavonen, J., Naud, P., Salmerón, J., Wheeler, C.M., Chow, S.N., Apter, D., Kitchener, H., Castellsague, X., Teixeira, J.C., Skinner, S.R., Hedrick, J., Jaisamrarn, U., Limson, G., Garland, S., Szarewski, A., Romanowski, B., Aoki, F.Y., 
Schwarz, T.F., Poppe, W.A., Bosch, F.X., Jenkins, D., Hardt, K., Zahaf, T., Descamps, D., Struyf, F., Lehtinen, M. and Dubin, G. (2009) Efficacy of human papillomavirus (HPV)-16/18 AS04-Adjuvanted Vaccine against Cervical Infection and Precancer Caused by Oncogenic HPV Types (PATRICIA): Final Analysis of a Double-Blind, Randomised Study in Young Women. Lancet, 374, 301-314.

http://dx.doi.org/10.1016/S0140-6736(09)61248-4

[12] Harper, .D.M., Franco, E.L., Wheeler, C.M., Moscicki, A.B., Romanowski, B., Roteli-Martins, C.M., Jenkins, D., Schuind, A., Costa Clemens, S.A. and Dubin, G. (2006) Sustained Efficacy up to 4.5 Years of a Bivalent L1 VirusLike Particle Vaccine against Human Papillomavirus Types 16 and 18: Follow-Up from a Randomised Control Trial. Lancet, 367, 1247-1255. http://dx.doi.org/10.1016/S0140-6736(06)68439-0

[13] Harper, D.M. (2008) Impact of Vaccination with Cervarix (Trade Mark) on Subsequent HPV-16/18 Infection and Cervical Disease in Women 15-25 Years of Age. Gynecologic Oncology, 110, S11-S17. http://dx.doi.org/10.1016/j.ygyno.2008.06.029

[14] David, M.P., Van Herck, K., Hardt, K., Tibaldi, F., Dubin, G., Descamps, D. and Van Damme, P. (2009) Long-Term Persistence of Anti-HPV-16 and -18 Antibodies Induced by Vaccination with the AS04-Adjuvanted Cervical Cancer Vaccine: Modeling of Sustained Antibody Responses. Gynecologic Oncology, 115, S1-S6. http://dx.doi.org/10.1016/j.ygyno.2009.01.011

[15] Hayashi, Y., Shimizu, Y., Netsu, S., Hanley, S. and Konno, R. (2012) High HPV Vaccination Uptake Rates for Adolescent Girls after Regional Governmental Funding in Shiki City, Japan. Vaccine, 30, 5547-5550. http://dx.doi.org/10.1016/j.vaccine.2012.06.038

[16] Kobayashi, H., Nakajima, Y. and Akasaki, M. (2012) Factors Influencing Coverage of Human Papillomavirus Vaccination: Questionnaire Survey of Local Governments in Nara Prefecture about the HPV Vaccination Program and Communication Campaigns to Promote the Program. Progress in Medicine, 32, 753-759.

[17] Miyagi, E. (2011) Research Report Supported by Health and Labour Sciences Research Grant. http://kanagawacc.jp/pdf/23report.pdf

[18] Hughes, J., Cates, J.R., Liddon, N., Smith, J.S., Gottlieb, S.L. and Brewer, N.T. (2009) Disparities in How Parents Are Learning about the Human Papillomavirus Vaccine. Cancer Epidemiology, Biomarkers \& Prevention, 18, 363-372. http://cebp.aacrjournals.org/content/18/2/363.long http://dx.doi.org/10.1158/1055-9965.EPI-08-0418

[19] McRee, A.L., Reiter, P.L. and Brewer, N.T. (2012) Parents’ Internet Use for Information about HPV Vaccine. Vaccine, 30, 3757-3762. http://dx.doi.org/10.1016/j.vaccine.2011.11.113 http://dx.doi.org/10.1016/j.vaccine.2011.11.113

[20] Marchand, E., Glenn, B.A. and Bastani, R. (2012) Low HPV Vaccine Coverage among Female Community College Students. Journal of Community Health, 37, 1136-1144. http://www.ncbi.nlm.nih.gov/pmc/articles/PMC3747828/ http://dx.doi.org/10.1007/s10900-012-9572-x

[21] Darden, P.M., Thompson, D.M., Roberts, J.R., Hale, J.J., Pope, C., Naifeh, M. and Jacobson, R.M. (2013) Reasons for Not Vaccinating Adolescents: National Immunization Survey of Teens, 2008-2010. Pediatrics, 131, 645-651. http://pediatrics.aappublications.org/content/131/4/645.long http://dx.doi.org/10.1542/peds.2012-2384

[22] Kester, L.M., Zimet, G.D., Fortenberry, J.D., Kahn, J.A. and Shew, M.L. (2013) A National Study of HPV Vaccination of Adolescent Girls: Rates, Predictors, and Reason for Non-Vaccination. Maternal and Child Health Journal, 17, 879885. http://dx.doi.org/10.1007/s10995-012-1066-z

[23] Sotiriadis, A., Dagklis, T., Siamanta, V., Chatzigeorgiou, K. and Agorastos, T. (2012) Increasing Fear of Adverse Effects Drops Intention to Vaccinate after the Introduction of Prophylactic HPV Vaccine. Archives of Gynecology and Obstetrics, 285, 1719-1724. http://dx.doi.org/10.1007/s00404-011-2208-z

[24] Teitelman, A.M., Stringer, M., Nguyen, G.T., Hanlon, A.L., Averbuch, T. and Stimpfel, A.W. (2011) Social Cognitive and Clinical Factors Associated with HPV Vaccine Initiation among Urban, Economically Disadvantaged Women. Journal of Obstetric, Gynecologic, \& Neonatal Nursing, 40, 691-701. http://dx.doi.org/10.1111/j.1552-6909.2011.01297.x

[25] Chou, B., Krill, L.S., Horton, B.B., Barat, C.E. and Trimble, C.L. (2011) Disparities in Human Papillomavirus Vaccine Completion among Vaccine Initiators. Obstetrics \& Gynecology, 118, 14-20. http://dx.doi.org/10.1097/AOG.0b013e318220ebf3

[26] Liddon, N.C., Leichliter, J.S. and Markowitz, L.E. (2012) Human Papillomavirus Vaccine and Sexual Behavior among Adolescent and Young Women. American Journal of Preventive Medicine, 42, 44-52. http://dx.doi.org/10.1016/j.amepre.2011.09.024

[27] Glaser, B.G. and Strauss, A.L. (1967) The Discovery of Grounded Theory: Strategies for Qualitative Research. Aldine, Chicago. 
[28] Oda, H., Kasuga, T., Yamamoto, N., Kasuga, T. and Miyaji, N. (2002) Shitsuteki Kenkyu Nyumon. Shunjusha, Tokyo.

[29] Katz, I.T., Ware, N.C., Gray, G., Haberer, J.E., Mellins, C.A. and Bangsberg, D.R. (2010) Scaling up Human Papillomavirus Vaccination: A Conceptual Framework of Vaccine Adherence. Sex Health, 7, 279-286.

http://www.ncbi.nlm.nih.gov/pmc/articles/PMC3141556/

http://dx.doi.org/10.1071/SH09130

[30] Van Hecke, A., Beeckman, D., Grypdonck, M., Meuleneire, F., Hermie, L. and Verhaeghe, S. (2013) Knowledge Deficits and Information-Seeking Behavior in Leg Ulcer Patients: An Exploratory Qualitative Study. Journal of Wound, Ostomy \& Continence Nursing, 40, 381-387. http://dx.doi.org/10.1097/WON.0b013e31829a2f4d

[31] McRee, A.L., Gottlieb, S.L., Reiter, P.L., Dittus, P.J., Halpern, C.T. and Brewer, N.T. (2012) Human Papillomavirus Vaccine Discussions: An Opportunity for Mothers to Talk with Their Daughters about Sexual Health. Sexually Transmitted Diseases, 39, 394-401. http://www.ncbi.nlm.nih.gov/pmc/articles/PMC3335343/ http://dx.doi.org/10.1097/OLQ.0b013e318248aaa0

[32] Waller, J., Marlow, L.A. and Wardle, J. (2006) Mothers’ Attitudes towards Preventing Cervical Cancer through Human Papillomavirus Vaccination: A Qualitative Study. Cancer Epidemiology, Biomarkers \& Prevention, 15, 12571261. http://cebp.aacrjournals.org/content/15/7/1257.long http://dx.doi.org/10.1158/1055-9965.EPI-06-0041

[33] Shafer, A., Cates, J.R., Diehl, S.J. and Hartmann, M. (2011) Asking Mom: Formative Research for an HPV Vaccine Campaign Targeting Mothers of Adolescent Girls. Journal of Health Communication, 16, 988-1005. http://dx.doi.org/10.1080/10810730.2011.571343

[34] The Information Center for Health and Social-Care (2006) Cervical Screening Programme_England, 2005-2006. http://www.hscic.gov.uk/pubs/csp0506

[35] Gamble, H.L., Klosky, J.L., Parra, G.R. and Randolph, M.E. (2010) Factors Influencing Familial Decision-Making Regarding Human Papillomavirus Vaccination. Journal of Pediatric Psychology, 35, 704-715.

http://jpepsy.oxfordjournals.org/content/35/7/704.long

http://dx.doi.org/10.1093/jpepsy/jsp108 
Scientific Research Publishing (SCIRP) is one of the largest Open Access journal publishers. It is currently publishing more than 200 open access, online, peer-reviewed journals covering a wide range of academic disciplines. SCIRP serves the worldwide academic communities and contributes to the progress and application of science with its publication.

Other selected journals from SCIRP are listed as below. Submit your manuscript to us via either submit@scirp.org or Online Submission Portal.
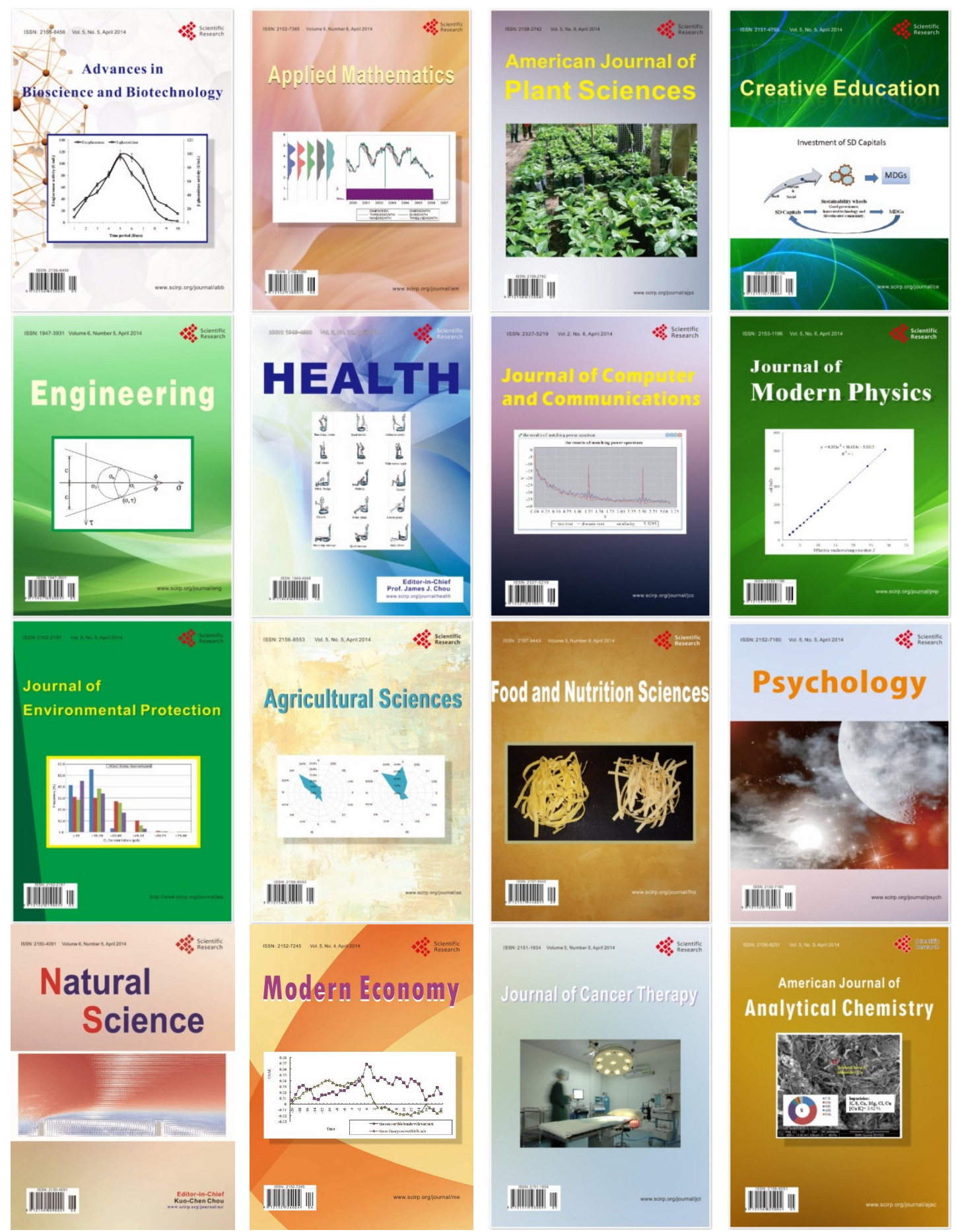